Femke M. Seesing, MSc

Hans J. Groenewoud, MSc

Gea Drost, MD, PhD

Baziel G.M. van Engelen,

MD, Professor

Gert Jan van der Wilt, Professor

Correspondence to Dr. Seesing: femke.seesing@radboudumc.n

\title{
Cost-effectiveness of shared medical appointments for neuromuscular patients
}

\section{企}

\section{ABSTRACT}

Objective: To assess whether shared medical appointments (SMAs) for neuromuscular patients represent a way of using clinicians' time efficiently without compromising quality of care for patients.

Methods: Patients with a chronic neuromuscular disease (NMD) $(n=272)$ were randomly allocated to either an SMA or a regular individual annual appointment and followed up for a period of 6 months. Data on resource utilization and quality of life (EQ-5D) were collected prospectively, using a health care perspective. Incremental costs and changes in quality-adjusted life-years (QALYs) were computed using a probabilistic decision model. Factors critical to the incremental cost-effectiveness of SMAs were explored in sensitivity analyses.

Results: No substantial differences between SMAs and individual visits in terms of costs per QALY were found (incremental cost-effectiveness ratio $€-960.00 ; 95 \%$ confidence interval $€-34,600.00, €+36,800.00)$. Sensitivity analyses showed that the cost-effectiveness ratio was particularly sensitive to SMA group size and proportion of patients seeing their treating neurologist.

Conclusions: Cost-effectiveness of SMAs did not show a significant difference vs that of individual appointments based on data from our randomized controlled trial. On the other hand, we were able to show that a minimum of 6 patients per SMA and 75\% of patients attending their treating neurologist are specific conditions under which SMAs qualify as a cost-effective alternative. This implies that SMAs may be a means to increase productivity of the physician without compromising quality of care.

Classification of evidence: This study provides Class III evidence that SMAs are not significantly more cost-effective than individual appointments for patients with NMDs. The study lacks the precision to exclude important differences in cost-effectiveness between SMAs and individual appointments. Neurology ${ }^{\circledR}$ 2015;85:619-625

\section{GLOSSARY}

ICER = incremental cost-effectiveness ratio; NMD = neuromuscular disease; $\mathbf{Q A L Y}=$ quality-adjusted life-year; $\mathbf{R C T}=$ randomized controlled trial; SMA = shared medical appointment

Time is a precious resource in the context of patient care. ${ }^{1}$ Patients hope to find attentive concern on the part of the clinician. On the other hand, in the interest of cost control, less rather than more time per patient is available. The fact that productivity gains in health care do not match those in other areas is an important factor contributing to the rise in health care costs. ${ }^{2}$ The resulting increase in time pressure is not always experienced in the same way. Clinicians who became patients realized how time can be experienced differently. ${ }^{3}$ Recognizing these developments in our own department, we wondered whether shared medical appointments (SMAs) (where multiple patients and their partners with the same diagnosis are seen by the neurologist at the same time) might help to resolve this problem. In a way, this creates more clinician time for the patient, although not exclusively for him or her individually. Also, the patient may benefit from knowledge and experiences of other patients, contributing to a

From the Departments of Neurology (F.M.S., G.D., B.G.M.v.E.) and Health Evidence (H.J.G., G.J.v.d.W.), Radboud University Medical Centre, Nijmegen; and the Departments of Neurology and Neurosurgery (G.D.), University of Groningen, University Medical Center Groningen, the Netherlands.

Go to Neurology.org for full disclosures. Funding information and disclosures deemed relevant by the authors, if any, are provided at the end of the article. 
decrease in resource utilization. ${ }^{4,5}$ To be sure, there is a tradeoff, since some patients may prefer not to discuss certain issues in the presence of others. We evaluated this approach in a randomized controlled trial (RCT). ${ }^{6}$ In this

Table 1 Baseline participant characteristics for the 2 study groups

\begin{tabular}{|c|c|c|}
\hline & $\begin{array}{l}\text { Shared medical } \\
\text { appointment } \\
(n=123)\end{array}$ & $\begin{array}{l}\text { Individual } \\
\text { appointment } \\
\text { ( } \mathrm{n}=112)\end{array}$ \\
\hline Age, $y$, mean (SD) & 50 (13.5) & $52(13.3)$ \\
\hline Men & 63 (51.2) & $62(55.4)$ \\
\hline Partner relationship & $86(70.5)$ & 79 (72.5) \\
\hline \multicolumn{3}{|l|}{ Diagnoses } \\
\hline Myotonic dystrophy type 1 & 45 (36.6) & $30(26.8)$ \\
\hline Facioscapulohumeral muscular dystrophy & 24 (19.5) & $23(20.5)$ \\
\hline $\begin{array}{l}\text { Nondystrophic myotonias: chloride and sodium } \\
\text { channelopathies }\end{array}$ & $9(7.3)$ & $12(10.7)$ \\
\hline Myositis: dermatomyositis and polymyositis & $7(5.7)$ & $12(10.7)$ \\
\hline Polyneuropathy & $14(11.4)$ & 15 (13.4) \\
\hline Inclusion body myositis & 4 (3.3) & $5(4.5)$ \\
\hline Chronic progressive external ophthalmoplegia & 4 (3.3) & $1(0.9)$ \\
\hline McArdle disease & $5(4.1)$ & $3(2.7)$ \\
\hline Oculopharyngeal muscular dystrophy & $11(8.9)$ & $11(9.8)$ \\
\hline \multicolumn{3}{|l|}{$\begin{array}{l}\text { Modified Rankin Scale score (higher scores } \\
\text { indicate more severe symptoms) }\end{array}$} \\
\hline 0 & $4(3.4)$ & $8(8.2)$ \\
\hline 1 & $19(16.0)$ & $13(13.4)$ \\
\hline 2 & 39 (32.8) & $35(36.1)$ \\
\hline 3 & $21(17.6)$ & $14(14.4)$ \\
\hline 4 & 34 (28.6) & $27(27.8)$ \\
\hline 5 & $2(1.7)$ & $0(0)$ \\
\hline \multicolumn{3}{|l|}{ Employment status } \\
\hline Studying/in training & $2(1.7)$ & 2 (1.9) \\
\hline Paid work & 42 (36.5) & 33 (31.1) \\
\hline Housework/volunteer work & $8(7.0)$ & $7(6.6)$ \\
\hline Seeking work & $2(1.7)$ & $1(0.9)$ \\
\hline (Partially) medically retired & 36 (31.3) & 37 (34.9) \\
\hline Retired & $25(21.7)$ & $26(24.5)$ \\
\hline Self-reported comorbidity & 85 (70.2) & $65(60.2)$ \\
\hline Cardiac symptoms & 19 (15.8) & $16(15.2)$ \\
\hline Depression & 11 (9.2) & $3(2.9)$ \\
\hline Eye/stare symptoms & 20 (16.7) & 14 (13.3) \\
\hline Gastroenterologic disease & 28 (23.2) & 20 (19.0) \\
\hline Pain & $24(20.0)$ & 15 (14.3) \\
\hline Thyroid symptoms & $6(5.0)$ & $2(1.9)$ \\
\hline Appointment with treating neurologist & 20 (16.3) & $34(30.6)$ \\
\hline EQ-5D index, median (interquartile range) & $0.78(0.65-0.81)$ & $0.78(0.65-0.81)$ \\
\hline
\end{tabular}

Data are $\mathrm{n}(\%)$ unless stated otherwise. complementary article, we report the results on resource use and quality of life. In a decision analytic model, we explored under which conditions SMAs for this patient population might qualify as an efficient and effective option.

METHODS Standard protocol approvals, registrations, and patient consents. This RCT was approved by the regional medical ethics committee and written informed consent was obtained from all participants. The trial is registered with the Dutch Trial Register (www.trialregister.nl) as NTR1412.

Study design. The study comprises an economic evaluation from the health care perspective and was conducted in parallel with an RCT. The methods and results pertaining to the clinical effectiveness of the RCT have been described in detail elsewhere. ${ }^{6,7}$ In brief, we conducted an RCT with a 6-month follow-up where patients with neuromuscular disease (NMD) were randomized to either an SMA or an individual appointment with one of the 2 participating neuromuscular neurologists (B.G.M.v.E., G.D.) at the outpatient clinic of the Neurology Department of the Radboud University Medical Centre.

The primary research question was to evaluate whether a single SMA is more cost-effective for patients with chronic neuromuscular disorders as compared to individual medical appointments.

The secondary research questions were to analyze under which conditions SMAs for patients with NMD qualify as an efficient and effective alternative to individual appointments and what effect SMAs have on the productivity of participating neurologists.

This study provides Class III evidence on whether SMAs are more cost-effective than individual appointments for patients with NMDs.

Participants. Patients were identified through the Computer Registry of All Myopathies and Polyneuropathies (CRAMP), the Dutch database of patients with NMD, and recruited between March 2009 and March 2011. ${ }^{8}$ Patients were eligible when they were diagnosed with one of the selected chronic NMDs (table 1), were over 18 years of age, were currently in the care of our department, and had not seen their neurologist 6 months prior to study commencement. Patients were recruited from the practice of the study neurologists (B.G.M.v.E., G.D.) as well as from colleague neurologists of our department. Exclusion criteria were severe hearing problems or insufficient command of the Dutch language. ${ }^{7}$ Eligible patients were invited to participate together with their partners or chief informal caregiver.

Randomization. Patient randomization (1:1) was computergenerated (by dedicated software), concealed, and balanced for diagnoses. Due to the nature of the intervention, physicians and participants could not be blinded to group assignment, but the statistician who conducted the analyses was blinded to treatment allocation.

Intervention. Patients and partners randomized to the SMA group were invited to attend an SMA of 1.5-2 hours as a substitute for their regular annual visit. During an SMA, 1 of 2 specialist neurologists (either B.G.M.v.E. or G.D.) saw 5-8 patients with the same diagnosis and their partners simultaneously, addressing the same topics that are commonly covered during the yearly follow-up appointment. The neurologist was supported by a group mentor who facilitated the group process by fostering interaction between patients and partners and by managing time. 
Both neurologists and the group mentor had received training in conducting SMAs prior to the study.

Participants randomized to the control group were seen individually by one of the participating neurologists (B.G.M.v.E. or G.D.) during their regular annual 20-to-30-minute appointment. For both intervention groups, care was tailored to the needs of the patients and their partners. Prescriptions, referrals, and medical record-keeping were as usual.

Outcome measures. Utilities were evaluated by the EuroQol EQ-5D index scale for patients, a standardized instrument designed to determine health-related quality of life in terms of quality-adjusted life-years (QALYs). ${ }^{9}$ To measure the use of resources, the following items from the Client Service Receipt Inventory ${ }^{10}$ were included: visits to a general practitioner, medical specialist, physiotherapist, occupational therapist, psychologist, psychiatrist, or social worker; hospital admissions; medication; home care and domestic help.

Outcome measures were obtained through self-reported questionnaires unless stated otherwise. Participants received these by mail at home 4 weeks before and 1, 12, and 24 weeks after the intervention. Severity of disease according to the modified Rankin Scale was established by physicians during the appointments.

Valuation of the cost items. Costs were calculated by multiplying volumes of resources by the cost price per resource unit (table 2). Cost prices were based on the Dutch guidelines for economic evaluation in health care unless stated otherwise. ${ }^{11}$ Domestic help was quantified in hours worked, adopting national average hourly wage rates for domestic cleaners. All prices were converted to the year 2011 by means of the Dutch consumer price index and expressed in euros (at which time 1 euro was equivalent to British $£ 0.85$ and USD \$1.31). ${ }^{12}$
Intervention costs. Since no unit cost price was available for SMAs, we calculated SMA cost price on the basis of the actual time spent by the consultant neurologist and group mentor (a specialist nurse or equivalent). Cost prices of the health professionals' time were based on the Dutch guidelines for economic evaluation in health care and converted to 2011 corresponding with the valuation of the cost items. ${ }^{11}$ No adjustments were made for the number of patients per SMA since this did not affect its organization or duration.

Statistical analysis. Descriptive statistics were used to generate baseline participant characteristics. Participant data were included for analysis when at least the baseline and 1 effect measurement was available. Remaining missing patient data on the volumes of resources used and QALYs were imputed with multiple imputation techniques. ${ }^{13}$ Imputation was executed 5 times and the weighted means of cost variables and effects over the follow-up time were calculated. QALYs were calculated from baseline to follow-up (6-month periods) using the area under the curve method and compared with a $t$ test. Analyses were conducted on the basis of the intention-to-treat principle. A $p$ value of $<0.05$ was regarded as significant and SPSS was used to conduct the analyses of total costs and QALYs.

Probabilistic decision model. To compare the cost-effectiveness of an SMA with an individual appointment, a probabilistic decision model was developed. The model consisted of 2 main branches, SMA and individual appointment, each allowing for the probability that a patient was seen by his own neurologist or not. (See figure e-1 on the Neurology Web site at Neurology.org for a schematic figure of the model structure.) Model parameters for expected costs (in euros) and effects (in QALYs) as well as number of patients per SMA were extracted from the results of

\begin{tabular}{|c|c|c|c|c|c|c|}
\hline \multirow[t]{3}{*}{ Table 2} & \multicolumn{6}{|c|}{$\begin{array}{l}\text { Cost variables, resources used, mean price per unit, and average costs per patient for the shared and the individual appointment } \\
\text { groups }\end{array}$} \\
\hline & & \multicolumn{2}{|c|}{$\begin{array}{l}\text { Average no. of resources } \\
\text { used during follow-up, total } \\
\text { no. of units/N }\end{array}$} & \multirow[b]{2}{*}{$\begin{array}{l}\text { Unit cost price, } € \text {, } \\
2011\end{array}$} & \multicolumn{2}{|c|}{$\begin{array}{l}\text { Mean (range) cost per patient during follow-up, } € \text {, total costs per } \\
\text { units/N }\end{array}$} \\
\hline & & SMA & $\begin{array}{l}\text { Individual } \\
\text { appointment }\end{array}$ & & SMA & Individual appointment \\
\hline \multicolumn{2}{|c|}{ General practitioner (visits) } & 2.0 & 1.6 & $28.59^{a}$ & $57.11(0-686.11)$ & $45.96(0-343.06)$ \\
\hline \multicolumn{2}{|c|}{ Medical specialist (visits) } & 1.7 & 1.8 & $73.51^{\mathrm{a}}$ & $126.58(0-882.14)$ & $133.80(0-1,396.73)$ \\
\hline \multicolumn{2}{|c|}{ Physiotherapist (visits) } & 14.3 & 17.0 & $36.76^{a}$ & $525.64(0-3,528.58)$ & $623.96(0-3,675.60)$ \\
\hline \multicolumn{2}{|c|}{ Occupational therapist (visits) } & 1.2 & 1.1 & $22.46^{a}$ & $27.34(0-899.33)$ & $24.41(0-808.63)$ \\
\hline \multicolumn{2}{|c|}{ Hospital admissions (no. of nights) } & 0.6 & 1.2 & $466.60^{\mathrm{a}}$ & $280.12(0-7,465.55)$ & $543.89(0-14,464.51)$ \\
\hline \multicolumn{2}{|c|}{ Medication (dosages) } & 31.7 & 38.9 & Variable $^{\mathrm{b}}$ & $36.71(0-250.18)$ & $36.72(0-364.52)$ \\
\hline \multicolumn{2}{|c|}{ Home care (hours) } & 2.3 & 1.3 & $35.91^{\mathrm{a}}$ & $82.12(0-1,651.86)$ & $46.25(0-574.56)$ \\
\hline \multicolumn{2}{|c|}{ Domestic help (hours) } & 1.5 & 2.3 & 12.5 & $18.86(0-262.50)$ & $29.22(0-500.00)$ \\
\hline \multicolumn{5}{|c|}{ Total costs } & 1,317.44 (104.50-8,846.16) & $1,646.89$ (131.71-16,221.05) \\
\hline
\end{tabular}

Abbreviation: SMA = shared medical appointment.

Mean costs based on pooled data from 5 imputed datasets.

a Unit cost prices derived from the Dutch guidelines for health economic evaluations (Hakkaart-van Roijen et al., 201011).

b Unit cost prices as derived from the Dutch list of drug costs (www.medicijnkosten.nl). 
our RCT for both treatment groups (table 3). The incremental cost-effectiveness ratio (ICER) was calculated and represented visually as an incremental cost-effectiveness scatterplot showing pairs of incremental cost and effectiveness values from $n=1,000$ iterations. The probability that an SMA is cost-effective was calculated using a willingness-to-pay of $€ 80,000.00$ per QALY, a threshold suggested by the Council for Public Health and Health Care of The Netherlands. ${ }^{14}$ The impact of model parameters on the ICER were explored in 1-way and 2-way sensitivity analyses. TreeAge Pro and Microsoft Excel were used to conduct the decision modeling.

RESULTS Participants. In total, 272 patients were included in the study, of whom 143 were randomly assigned to the SMA group and 129 to the individual appointment group. For 37 patients, fewer than 2 measurements were available, resulting in a total of 235 datasets for analysis. The patients in the 2 groups were similar at baseline with respect to most variables (table 1). In the SMA group, slightly more patients were diagnosed with myotonic dystrophy type 1, fewer patients were seen by their treating neurologist, and slightly more patients reported comorbidity. These differences were corrected for in the statistical analyses.

Outcome. Volumes of resource use, unit cost prices, and average costs for both groups are presented in table 2. The pooled average cost of resources cumulated over the 6-month follow-up period was

\begin{tabular}{|c|c|c|c|c|}
\hline \multicolumn{5}{|c|}{ Input parameters of the probabilistic decision model } \\
\hline Parameter & $\begin{array}{l}\text { Expected } \\
\text { value }\end{array}$ & SD & $95 \% \mathrm{Cl}$ & Source \\
\hline \multicolumn{5}{|c|}{$\begin{array}{l}\text { Probability of attending treating } \\
\text { neurologist }\end{array}$} \\
\hline SMA & 0.75 & 0.04 & $0.67-0.83$ & Clinical experience \\
\hline Individual appointment & 0.90 & 0.03 & $0.83-0.95$ & Clinical experience \\
\hline No. of patients per SMA & $3-9$ & 1 & $6-10$ & Empirical data \\
\hline \multicolumn{5}{|c|}{ Total cost resources used, $€$} \\
\hline \multicolumn{5}{|l|}{ SMA } \\
\hline Treating neurologist & $€ 365$ & 356 & $11-1,330$ & Empirical data \\
\hline Other neurologist & $€ 828$ & 1,057 & $2-3,655$ & Empirical data \\
\hline \multicolumn{5}{|l|}{ Individual appointment } \\
\hline Treating neurologist & $€ 419$ & 616 & $0-2,245$ & Empirical data \\
\hline Other neurologist & $€ 1,198$ & 1,876 & $0-6,397$ & Empirical data \\
\hline \multicolumn{5}{|l|}{ Effectiveness (QALY) } \\
\hline \multicolumn{5}{|l|}{ SMA } \\
\hline Treating neurologist & 0.67 & 0.18 & $0.29-0.96$ & Empirical data \\
\hline Other neurologist & 0.70 & 0.18 & $0.30-0.97$ & Empirical data \\
\hline \multicolumn{5}{|l|}{ Individual appointment } \\
\hline Treating neurologist & 0.73 & 0.18 & $0.30-0.98$ & Empirical data \\
\hline Other neurologist & 0.74 & 0.15 & $0.38-0.97$ & Empirical data \\
\hline
\end{tabular}

Abbreviations: $\mathrm{Cl}=$ confidence interval; $\mathrm{QALY}=$ quality-adjusted life-year; SMA = shared medical appointment.
$€ 1,317.44$ (range $€ 104.50-€ 8,846.16$ ) per patient for the SMA group and $€ 1,646.89$ (range $€ 131.71-$ $€ 16,221.05)$ for the individual appointment group. The mean QALYs over the 6-month follow-up period for the SMA group was 0.69 (SE 0.14) and for the individual appointment group 0.74 (SE 0.16).

Monte Carlo modeling. A Monte Carlo simulation resulted in an incremental loss of 0.05 QALYs and a $€ 48$ reduction in costs for the 6-month follow-up period for the SMA/individual appointment contrast. In other words, for 1 QALY lost, health care could gain $€ 960$ per patient when SMAs would be implemented (ICER $=€-960.00 ; 95 \%$ confidence interval $€-34,600.00$, $€ 36,800.00)$. The probability that SMAs are more cost-effective than individual visits was $39 \%$ at a willingness-to-pay of $€ 80,000$ (figure 1).

Sensitivity analysis. Costs appeared significantly influenced by the number of patients per SMA and the proportion of patients seen by their treating neurologist. One-way sensitivity analysis of number of patients per SMA vs expected costs resulted in a threshold value of 6.2 patients (figure 2). Two-way sensitivity analyses of number of patients and probability of being seen by the treating neurologist showed that group visits can be more cost-effective than individual visits provided that SMA groups comprise more than 6 patients and that $75 \%$ of the patients are seen by their treating neurologist (figure not shown).

Productivity. With a mean of 16 minutes (range 1130 ), the neurologists spent less time per patient during the SMAs, given that the individual appointments lasted on average 25 minutes (range 20-30), as based on the actual attendance rates during the study period. Fewer than $8 \%$ of the patients required individual attention in addition to the SMA, a proportion that did not significantly influence the total time spent per patient in the intervention group.

DISCUSSION Using data from our RCT in chronic neuromuscular patients in a Monte Carlo simulation, we did not find any substantial significant differences between single SMAs and single conventional individual visits in terms of costs per QALYs. On the other hand, sensitivity analyses showed that a single SMA was more cost-effective than an individual appointment when a group size of more than 6 patients was maintained and $75 \%$ of these patients were seen by their treating neurologist. We have shown that if the abovementioned prerequisites are met, SMAs have the possibility to improve productivity for this specific population without compromising quality of care. Shared appointments are different in nature from one-on-one visits and require a different approach and mindset from both 


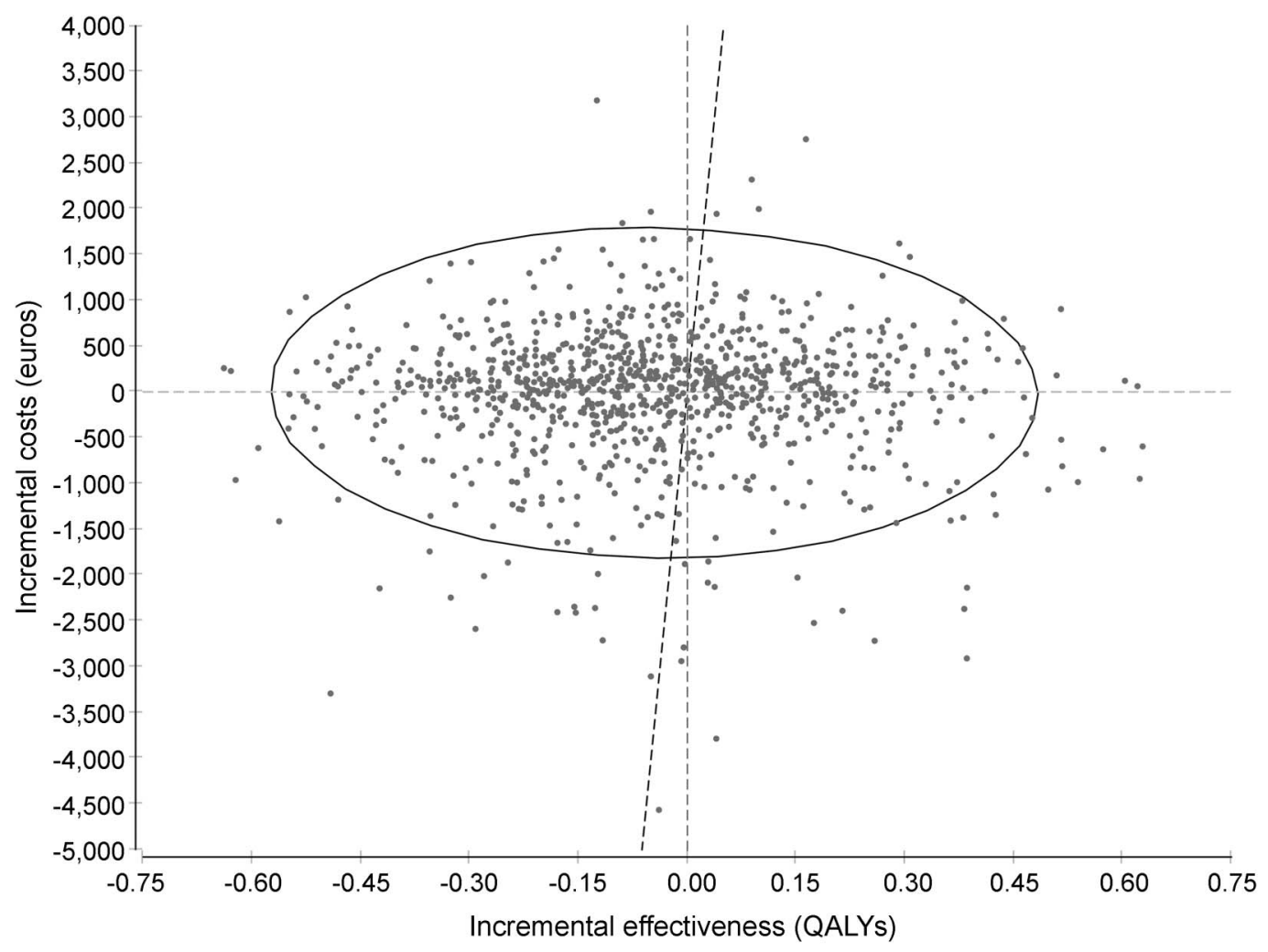

The incremental cost-effectiveness scatterplot includes a single set of points representing pairs of incremental cost and effectiveness values from the simulation results $(n=1,000)$ relative to a baseline. The slope intersecting the $x$ axis is the willingness-to-pay (WTP) threshold of $€ 80,000$. In addition to the WTP line, a 95\% confidence ellipse is drawn in the incremental cost-effectiveness scatterplot. The graph can be divided into 4 quadrants: southeast, shared medical appointments (SMAs) are less costly and more effective (SMAs dominate); southwest, SMAs are less costly and less effective; northwest, SMAs are more costly and less effective (individual appointments dominate); northeast, SMAs are more costly and more effective. The probability of SMAs being considered more cost-effective than individual appointments was 39\% at a WTP of $€ 80,000$. QALYs = quality-adjusted life-years.

the attending consultant and the patient, but as they provide patients an opportunity to share their knowledge and experiences as well as more time with their clinician, they may be more rewarding for both the patient and health professionals involved. However, we are aware that such advantages are largely speculative and need to be explored and substantiated in future studies.

Although several studies have reported a decline in resource utilization associated with SMAs, our findings suggest that no such savings should be expected for the SMAs we evaluated during a 6-month followup. This may be attributed to our distinctive diagnosis groups; the previous studies included patients with more common diseases like diabetes and heart failure. ${ }^{4,5,15}$ Attending a 90-minute group appointment with a neuromuscular neurologist and 6 to 8 peers could provide patients with a rare NMD with a wider variety of information and expertise, inducing more, instead of fewer, initial referrals. This is illustrated by the fact that resource utilization was significantly higher for patients who normally attend a general neurologist and during the study were seen by a specialized neuromuscular neurologist. Possibly underutilization of care is the case for several patients with a rare NMD and SMAs could make specialist care available to more patients. A potential decrease of resource utilization should be assessed in the light of fewer complications in the longer term.

We also offered the fact that we compared single SMAs with single individual appointments as an alternative explanation in our previous article; most other studies evaluated series of SMAs. ${ }^{6,16-18}$ Resource use might decrease after attending multiple SMAs, while patients gain knowledge over time and most referrals are being made during the first appointment.

Finally, although several authors emphasized that maintaining a sufficient SMA group size is important for both efficiency and interaction purposes, none have evaluated its impact. ${ }^{17,19}$ With our study we have shown that the cost-effectiveness of SMAs for NMD outpatients is particularly sensitive to SMA group size and to the proportion of patients seeing their treating neurologist. 
Figure 2 One-way sensitivity analyses of the costs for shared medical appointment group size

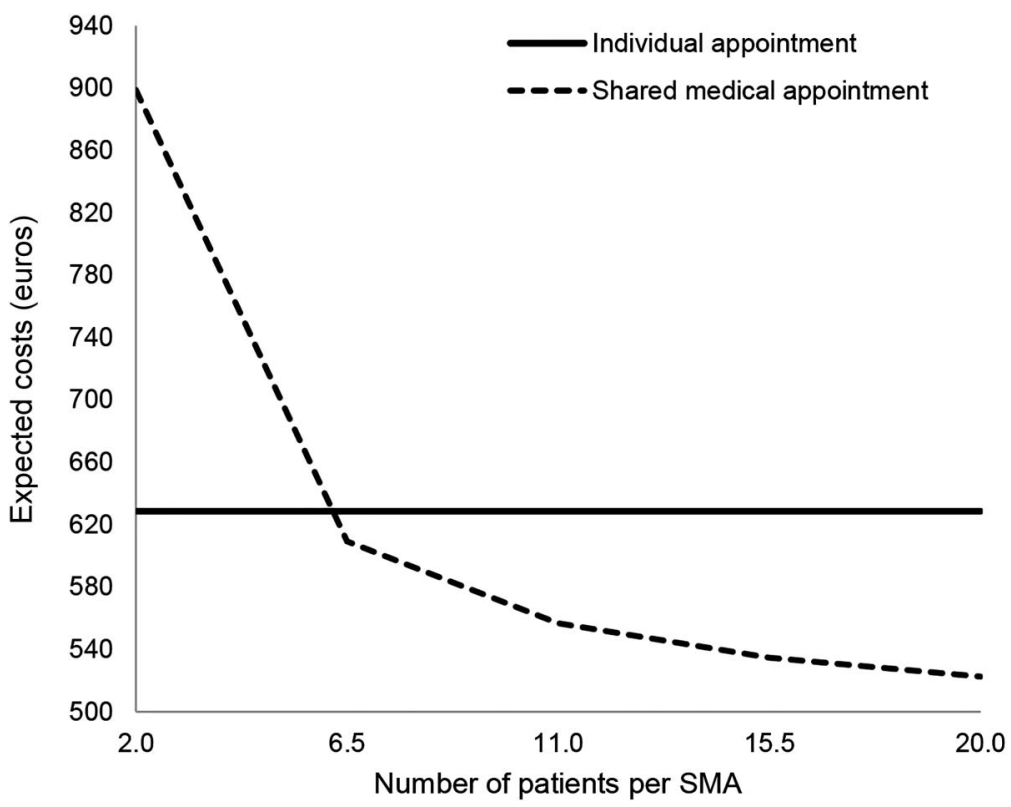

Probability of being seen by the treating neurologist in the shared medical appointment (SMA) group: 0.75 ; probability of being seen by treating neurologist in the individual group: 0.90 . Threshold value of $€ 628.60$ at 6.2 patients.

We performed an economic evaluation alongside a sizeable RCT, the robust design of which enabled us to align the intervention to usual care and to reliably compare the cost-effectiveness of a single SMA to that of an individual appointment. ${ }^{6}$ The wide range of neuromuscular disorders included in our cohort is reflective of clinical practice and enhances the generalizability of our results. Additionally, all missing volumes of resource use were imputed using multiple imputation techniques, which have been shown to be a reliable method for missing cost data. ${ }^{20}$ Then again, opting for a societal point of view for this economic evaluation may have strengthened the results, although we conjectured that the effects would be negligible. When interpreting the results it is important to take into account that patients attending an SMA together could influence each other. This could result in clustering effects and overrate the effect of the SMAs. Also, the self-reported comorbidity rates at baseline were slightly higher in the SMA group. Correcting for this slight imbalance in the analysis did not affect the resource utilization in the 2 groups. Another limitation is the study period; the 6-month follow-up may have been too short a period to unveil differences in costs, as it is plausible to assume that the number of referrals for the patients attending SMAs will drop after the initial group visit.

On a broad scale, controlled studies comparing the economic benefits of health care innovations that promote self-management skills in patients with a neuromuscular disorder are limited and additional RCTs with longer follow-up periods are needed to determine their long-term cost-effectiveness. More specifically, the potential effect of SMAs on resource utilization could be higher for patients for whom curative treatment options are available alongside symptomatic treatment. This would be an interesting question for further studies in this area. Follow-up research should also investigate which (groups of) patients benefit most from SMAs and which variables, besides group size and the proportion of patients seeing their own neurologist, influence cost-effectiveness most.

Although we were unable to detect consistent significant differences in terms of costs per QALY between an SMA and an individual appointment for chronic neuromuscular patients within the scope of our investigations, our data provided evidence suggesting that in this population the economic impact of SMAs depends on group size and the proportion of patients being seen by their own neurologist.

These conditions will concurrently help increase the productivity of the consulting physician without compromising quality of care. This adds important data to our earlier results on the effectiveness of SMAs for neuromuscular patients. ${ }^{6}$ Especially for rare chronic diseases such as NMDs, group visits could make high-quality outpatient care from a specialist neurologist available for more patients while at the same time empowering these patients and their partners or informal caregivers by reinforcing their selfmanagement skills. However, before SMAs can be more widely implemented, long-term effects on the costs and possible working mechanisms will need to be systematically explored and substantiated further.

\section{AUTHOR CONTRIBUTIONS}

B.G.M.v.E. and G.J.v.d.W. wrote the grant application and supervised the study. B.G.M.v.E., G.J.v.d.W., F.M.S., and G.D. contributed to the research design. F.M.S. was responsible for recruitment of the participants and the data collection. F.M.S., G.D., and B.G.M.v.E. implemented the intervention. H.J.G. was responsible for the sample size calculation. F.M.S. and H.J.G. were responsible for the data analysis and F.M.S., G.D., H.J.G., G.J.v.d.W., and B.G.M.v.E. took responsibility for data interpretation. F.M.S., G.J.v.d.W., and B.G.M.v.E. wrote the first draft of the manuscript. All authors reviewed the final draft. F.M.S. is the guarantor.

\section{ACKNOWLEDGMENT}

The authors thank the patients and partners who participated in the study; participating students for their contribution to the data collection; and Anneke Pelgröm for assisting in data collection.

\section{STUDY FUNDING}

ZonMw, The Netherlands Organisation for Health Research and Development (no. 170882703).

\section{DISCLOSURE}

F. Seesing has received research grants from ZonMw, the Netherlands Organisation for Health Research and Development (ZonMw no. 170882703), for this work, has received personal fees and consultancy fees from the Dutch Institute for Healthcare Improvement $\mathrm{CBO}$, and was 
consultant for FemkeSeesingAdvies outside this work. J. Groenewoud and G. Drost report no disclosures relevant to the manuscript. B. van Engelen reports personal fees from being the Research Director of the European Neuromuscular Centre (ENMC); received grants from Global FSH, Netherlands Organization for Scientific Research, Prinses Beatrix Fonds, and the Dutch FSHD Foundation, outside the submitted work; and has a patent pending on "Method of detecting autoantibodies from patients with sporadic inclusion body myositis" and license to commercialize knowledge in the patent mentioned above. G. van der Wilt reports no disclosures relevant to the manuscript. Go to Neurology.org for full disclosures.

Received February 5, 2015. Accepted in final form April 28, 2015.

\section{REFERENCES}

1. Braddock CH, Snyder L. The doctor will see you shortly. J Gen Intern Med 2005;20:1057-1062.

2. Baumol W. Children of performing arts, the economic dilemma: the climbing costs of health care and education. J Cult Econ 1996;20:183-206.

3. Klitzman R. "Patient-time, "doctor-time," and "institution-time": perceptions and definitions of time among doctors who become patients. Patient Educ Couns 2007; 66:147-155.

4. Scott JC, Conner DA, Venohr I, et al. Effectiveness of a group outpatient visit model for chronically ill older health maintenance organization members: a 2-year randomized trial of the cooperative health care clinic. J Am Geriatr Soc 2004;52:1463-1470.

5. Clancy DE, Dismuke CE, Magruder KM, Simpson KN, Bradford D. Do diabetes group visits lead to lower medical care charges? Am J Manag Care 2008;14:39-44.

6. Seesing FM, Drost G, Groenewoud J, van der Wilt GJ, van Engelen BG. Shared medical appointments improve QOL in neuromuscular patients: a randomized controlled trial. Neurology 2014;83:240-246.

7. Seesing FM, Drost G, van der Wilt GJ, van Engelen BG. Effects of shared medical appointments on quality of life and cost-effectiveness for patients with a chronic neuromuscular disease: study protocol of a randomized controlled trial. BMC Neurol 2011;11:106.

8. van Engelen BG, van Veenendaal H, van Doorn PA, et al. The Dutch neuromuscular database CRAMP (Computer Registry of All Myopathies and Polyneuropathies): development and preliminary data. Neuromuscul Disord 2007; 17:33-37.
9. EuroQoL Group. EuroQoL EG: a new facility for the measurement of health-related quality of life. Health Policy 1990;16:199-208.

10. Patel A, Rendu A, Moran P, Leese M, Mann A, Knapp M. A comparison of two methods of collecting economic data in primary care. Fam Pract 2005;22:323-327.

11. Hakkaart-van Roijen L, Tan S, Bouwmans C. Handleiding voor kostenonderzoek, methoden en standaard kostprijzen voor economische evaluaties in de gezondheidszorg. Geactualiseerde Versie 2010. Diemen, the Netherlands: College Voor Zorgverzekeringen; 2010.

12. CBS. Statistics Netherlands. Available at: http://www.cbs. nl/nl-NL/menu/themas/prijzen/publicaties/indexeringen/ modules/default.htm. Accessed February 26, 2014.

13. Donders ART, van der Heijden GJMG, Stijnen T, Moons KGM. Review: a gentle introduction to imputation of missing values. J Clin Epidemiol 2006;59:1087-1091.

14. The Council for Public Health and Health Care. Sensible and Sustainable Care. Zoetermeer, the Netherlands: The Council for Public Health and Health Care; 2006.

15. Lin A, Cavendish J, Boren D, Ofstad T, Seidensticker D. A pilot study: reports of benefits from a 6-month, multidisciplinary, shared medical appointment approach for heart failure patients. Mil Med 2008;173:1210-1213.

16. Trento M, Gamba S, Gentile L, et al. Rethink Organization to iMprove Education and Outcomes (ROMEO): a multicenter randomized trial of lifestyle intervention by group care to manage type 2 diabetes. Diabetes Care 2010;33:745-747.

17. Wagner EH, Grothaus LC, Sandhu N, et al. Chronic care clinics for diabetes in primary care: a system-wide randomized trial. Diabetes Care 2001;24:695-700.

18. Edelman D, Fredrickson SK, Melnyk SD, et al. Medical clinics versus usual care for patients with both diabetes and hypertension: a randomized trial. Ann Intern Med 2010; 152:689-696.

19. Edelman D, McDuffie JR, Oddone E, Gierisch JM, Nagi A, Williams JW. Shared Medical Appointments for Chronic Medical Conditions: A Systematic Review. Washington, DC: Department of Veterans Affairs; 2012.

20. Oostenbrink JB, Al MJ, Rutten-van Mölken MP. Methods to analyse cost data of patients who Withdraw in a clinical trial Setting. Pharmacoeconomics 2003;21: 1103-1112.

\section{It's Time to Plan for ICD-10, and the AAN Can Help}

All health care providers are required to transition to ICD-10 on October 1, 2015. Claims for services performed on or after this date with an ICD-9 code will not be processed and payments will be delayed. The AAN provides information and resources to help you make this a smooth transition, and has partnered with Complete Practice Resources to provide you with an affordable online project management tool to help walk you through each phase of the necessary preparation to ensure you're ready. Learn more at $A A N$.com/view/ICD10 and start your transition today! 


\section{Neurology}

\section{Cost-effectiveness of shared medical appointments for neuromuscular patients}

Femke M. Seesing, Hans J. Groenewoud, Gea Drost, et al.

Neurology 2015;85;619-625 Published Online before print July 17, 2015

DOI 10.1212/WNL.0000000000001857

This information is current as of July 17, 2015

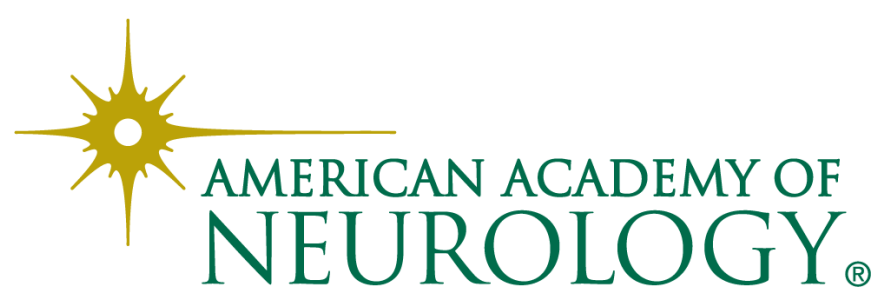




\section{Updated Information \& Services}

\section{Supplementary Material}

References

Subspecialty Collections

Permissions \& Licensing

\section{Reprints}

including high resolution figures, can be found at:

http://n.neurology.org/content/85/7/619.full

Supplementary material can be found at: http://n.neurology.org/content/suppl/2015/07/17/WNL.0000000000001 857.DC1

This article cites 16 articles, 3 of which you can access for free at: http://n.neurology.org/content/85/7/619.full\#ref-list-1

This article, along with others on similar topics, appears in the following collection(s):

\section{All Neuromuscular Disease}

http://n.neurology.org/cgi/collection/all_neuromuscular_disease

\section{Class III}

http://n.neurology.org/cgi/collection/class_iii

Clinical trials Randomized controlled ( $\overline{\mathbf{C}}$ ONSORT agreement)

http://n.neurology.org/cgi/collection/clinical_trials_randomized_control led_consort_agreement

Cost effectiveness/economic

http://n.neurology.org/cgi/collection/cost_effectiveness_economic Health policy

http://n.neurology.org/cgi/collection/health_policy

Models of care

http://n.neurology.org/cgi/collection/models_of_care

Information about reproducing this article in parts (figures,tables) or in its entirety can be found online at:

http://www.neurology.org/about/about_the_journal\#permissions

Information about ordering reprints can be found online:

http://n.neurology.org/subscribers/advertise

Neurology ${ }^{\circledR}$ is the official journal of the American Academy of Neurology. Published continuously since 1951, it is now a weekly with 48 issues per year. Copyright @ 2015 American Academy of Neurology. All rights reserved. Print ISSN: 0028-3878. Online ISSN: 1526-632X.

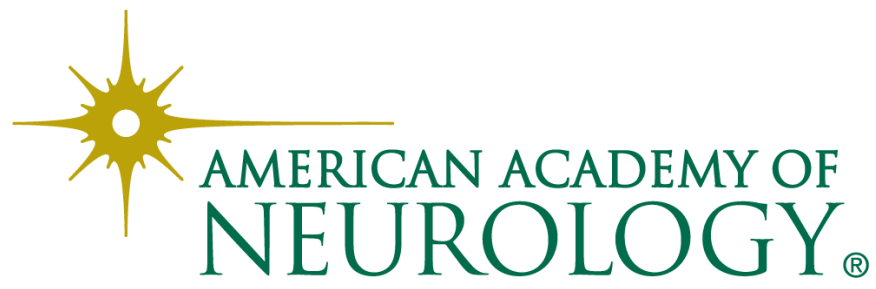

